\title{
ISOLATION AND CHARACTERISTICS OF LACTIC ACID BACTERIA ISOLATED FROM RIPE MULBERRIES IN TAIWAN
}

\author{
Yi-sheng Chen ${ }^{1, *}$, Hui-chung Wu ${ }^{1, \Delta}$, Fujitoshi Yanagida ${ }^{2}$ \\ ${ }^{1}$ Department of Biotechnology, Ming Chuan University, No. 5, De-Ming Rd., Gui-Shan Township, Taoyuan County 333, Taiwan; \\ ${ }^{2}$ The Institute of Enology and Viticulture, University of Yamanashi, 1-13-1 Kitashin, Kofu, Yamanashi 400-0005, Japan \\ Submitted: December 09, 2009; Returned to authors for corrections: February 09, 2010; Approved: April 26, 2010.
}

\begin{abstract}
The objective of this study was to isolate, characterize, and identify lactic acid bacteria (LAB) from ripe mulberries collected in Taiwan. Ripe mulberry samples were collected at five mulberry farms, located in different counties of Taiwan. Eighty-eight acid-producing cultures were isolated from these samples, and isolates were divided into classes first by phenotype, then into groups by restriction fragment length polymorphism (RFLP) analysis and sequencing of $16 \mathrm{~S}$ ribosomal DNA (rDNA). Phenotypic and biochemical characteristics led to identification of four bacterial groups (A to D). Weissella cibaria was the most abundant type of LAB distributed in four mulberry farms, and Lactobacillus plantarum was the most abundant LAB found in the remaining farm. Ten W. cibaria and one Lactococcus lactis subsp. lactis isolate produced bacteriocins against the indicator strain Lactobacillus sakei JCM $1157^{\mathrm{T}}$. These results suggest that various LAB are distributed in ripe mulberries and W. cibaria was the most abundant LAB found in this study.
\end{abstract}

Key words: lactic acid bacteria, mulberry, Weissella cibaria, bacteriocin, Taiwan.

\section{INTRODUCTION}

Mulberry (Morus australis) has been widely cultivated in China and southeastern Asia for thousands of years. The leaves of mulberry trees represent indispensable food for silkworms and the ripe fruits are edible and have been widely used in juices, wines and jams (23). In Taiwan, mulberry trees are widespread and the ripe fruits are always harvested in early April. The ripe fruit is sweet with a very mild flavor and is therefore popular in Taiwan. Although mulberries are very popular, they have not been studied in detail.
Isolation of lactic acid bacteria (LAB) from fruits and vegetables have frequently been reported $(2,3,7,14,18)$. However, studies on $\mathrm{LAB}$ associated with ripe mulberries remain scarce.

Bacteriocins produced by LAB have attracted special interest as potential alternative safe commercial food preservatives. LAB have been used as food and feed preservatives for centuries, and bacteriocin-producing LAB could replace chemical preservatives for the prevention of bacterial spoilage and the outgrowth of pathogenic bacteria in food products (6).

\footnotetext{
*Corresponding Author. Mailing address: Department of Biotechnology, Ming Chuan University, No. 5, De-Ming Rd., Gui-Shan Township, Taoyuan County 333, Taiwan.; Tel: +886-3-3507001\#3540 Fax: +886-3-3507001\#3540.; E-mail: yisheng@mail.mcu.edu.tw

${ }^{\Delta}$ The first two authors contributed equally to this work.
} 
The objectives of this study were to isolate $\mathrm{LAB}$ from ripe mulberries, identify the isolates at the species level, and screen them for antibacterial activity.

\section{MATERIALS AND METHODS}

\section{Sampling}

Samples for LAB isolation were collected from five mulberry farms (M1 to M5), which were respectively located in the following five counties in Taiwan: Tainan, Chiayi, Taichung, Miaoli and Taoyuan. The farms in these counties are listed from south to north and are 40-70 km apart. Three separate ripe fruit samples were randomly collected at each mulberry farm. The samples were taken aseptically and packaged into clean bags, then stored at $4^{\circ} \mathrm{C}$. Samples were analyzed within $24 \mathrm{~h}$ of acquisition at the mulberry farms.

\section{Isolation of LAB}

MRS (de Man, Rogosa, and Sharpe)-agar plates were used for the isolation of LAB. To distinguish acid-producing bacteria from other bacteria, $1 \% \mathrm{CaCO}_{3}$ was added to the MRS-agar plates. Each mulberry sample was crushed and mixed with $0.75 \% \mathrm{NaCl}$ solution. Dilutions of the mixed solution (10- to 1000-fold) were spread directly onto the surface of MRS-agar plates. Samples were incubated under anaerobic conditions (Mitsubishi AnaeroPak System, PackAnaero, Mitsubishi Gas Chemicals, Tokyo, Japan) at $30^{\circ} \mathrm{C}$ for 3 to 5 days. Colonies of acid-producing bacteria, identified by a clear zone around each colony, were randomly selected from MRS-agar plates and purified by replating on MRS-agar plates. Colonies were reselected and initially Gram stained and tested for production of catalase. Only Gram-positive, catalasenegative strains were selected. The selected strains were stored at $-80^{\circ} \mathrm{C}$ in $10 \%$ skim milk broth.

\section{Identification of isolates}

Restriction fragment length polymorphism (RFLP) analysis and sequence analysis of $16 \mathrm{~S}$ ribosomal DNA (rDNA) were used to classify and identify the bacterial isolates. DNA was isolated by using the methods described by Kozaki et al. (12). Polymerase chain reaction (PCR) was carried out using a Takara Ex Taq gene amplification PCR kit (Takara Bio, Shiga, Japan) to prepare reaction mixtures and performed on a Gene Amp PCR System 9700 (PerkinElmer Corp., Boston, MA, USA) following the methods described by Chen et al. (4). RFLP analysis of 16S rDNA was carried out with the methods described by Chen et al. (4). In this study, three restriction enzymes, AccII (CG/CG), HaeIII (GG/CC) (16), and AluI (AG/CT) (22) were used for grouping.

For sequence analysis of $16 \mathrm{~S}$ rDNA, the PCR products were purified with a Clean/Gel Extraction Kit (BioKit, Miaoli, Taiwan) and then sequenced with the following primer: 5'CTGCTGCCTCCCGTAG-3' (27F). DNA sequencing was performed using an ABI 3730 DNA Analyzer (Applied Biosystems, Foster City, CA, USA). Partial sequencing, approx. $1000 \mathrm{bp}$ ahead was performed and the sequence manually aligned with the software Genetyx-Win version 5.1. Sequence homologies were examined by comparing the sequences obtained with those in the DNA Data Bank of Japan (DDBJ; http://www.ddbj.nig.ac.jp/) using FASTA. During sequence comparison, an initial threshold of $99 \%$ homology was required when comparing the raw sequencing result, while $100 \%$ homology was obligated for the sequencing data with high signal to noise ratios.

\section{Detection of antibacterial activity}

The agar-well diffusion method as described by Onda et al. (15) was used to detect and determine the antibacterial activities of isolates. Lactobacillus sakei JCM $1157^{\mathrm{T}}$, Listeria monocytogenes ATCC 19111 and Helicobacter pylori ATCC $43504^{\mathrm{T}}$ were used as the indicator strains. L. monocytogenes was propagated in $\mathrm{PBN}$ broth $(\mathrm{pH}$ 7.3) with the following components: $0.5 \%$ peptone, $0.3 \%$ beef extract, and $0.8 \% \mathrm{NaCl}$. H. pylori was propagated in a Tryptic soy agar (Difco, Sparks, MD, USA) with 5\% defibrinated sheep blood added. To exclude the effect of lactic acid, antibacterial activity was later confirmed by $\mathrm{pH}$ adjustment (21). 


\section{Effect of enzymes on antimicrobial activity}

The effect of various enzymes on antimicrobial activity was determined by incubating $500 \mu \mathrm{L}$ of the neutralized and filter-sterilized cell-free supernatant with $20 \mu \mathrm{L}$ of the following enzyme solutions at a final concentration of 3 $\mathrm{mg} / \mathrm{mL}$ respectively: proteinase $\mathrm{K}(\mathrm{pH}$ 7.0), trypsin $(\mathrm{pH} 7.0)$ and catalase ( $\mathrm{pH}$ 7.0). Enzymes were purchased from Sigma Chemicals, St. Louis, MO, USA. After $5 \mathrm{~h}$ of incubation at 37 ${ }^{\circ} \mathrm{C}$, antimicrobial activity was determined by using agar-well diffusion assay. Untreated samples were used as control and $L$. sakei $\mathrm{JCM} 1157^{\mathrm{T}}$ was used as the indicator strain.

\section{RESULTS}

A total of 88 acid-producing bacterial strains were isolated from the samples collected in mulberry farms of Taiwan. Of these, 13 strains were isolated from farm M1, 18 from farm
M2, 20 from farm M3, 18 from farm M4, and 19 from farm M5 (Table 1). The 88 isolates were classified into four groups (A to D) based on cell morphology and the results of $16 \mathrm{~S}$ rDNA RFLP analysis (Fig. 1). Of these isolated short-rod strains, 54 were placed in group A, 14 in group B, and 18 in group D, because digestion of their DNA with AccII, HaeIII, and AluI gave the same RFLP patterns. The remaining coccal isolates were placed into group $\mathrm{C}$.

To identify the isolates, representative strains were randomly selected from each group, and 16S rDNA sequencing analysis was carried out. The results identified group A isolates as W. cibaria, group B as Leuconostoc pseudomesenteroides, group C as Lactococcus lactis subsp. lactis, and group D as Lactobacillus plantarum. The sequences determined in this study have been deposited in the DDBJ database with sequential accession numbers AB510744 to AB510757.

Table 1. Isolates from ripe mulberries

\begin{tabular}{|c|c|c|c|c|c|c|c|c|}
\hline 常 & $\begin{array}{c}\text { Strain } \\
\text { No. }\end{array}$ & Specie & 䔅 & Strain No. & Specie & 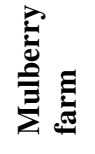 & Strain No. & Specie \\
\hline \multirow[t]{13}{*}{ M1 } & H041703 & W. cibaria & & H042046 & L. pseudomesenteroides & & I042210 & W. cibaria \\
\hline & H041706 & W. cibaria & M3 & I041701 & L. plantarum & & I042211 & W. cibaria \\
\hline & H041710 & W. cibaria & & I041702 & L. plantarum & & I042212 & W. cibaria \\
\hline & H041711 & W. cibaria & & I041703 & L. plantarum & & I042213 & W. cibaria \\
\hline & H041713 & W. cibaria & & I041704 & W. cibaria & & I042214 & W. cibaria \\
\hline & H041715 & W. cibaria & & I041705 & W. cibaria & & I042215 & W. cibaria \\
\hline & H041716 & W. cibaria & & I041706 & L. plantarum & & I042217 & W. cibaria \\
\hline & H041717 & W. cibaria & & I041707 & L. plantarum & & I042218 & W. cibaria \\
\hline & H041718 & W. cibaria & & I041708 & L. plantarum & & I042219 & W. cibaria \\
\hline & H041719 & W. cibaria & & I041709 & L. plantarum & M5 & I042501 & L. pseudomesenteroides \\
\hline & H041720 & W. cibaria & & I041710 & L. plantarum & & I042502 & W. cibaria \\
\hline & H041721 & W. cibaria & & I041711 & L. plantarum & & I042503 & W. cibaria \\
\hline & H041722 & W. cibaria & & I041712 & L. plantarum & & I042504 & W. cibaria \\
\hline \multirow[t]{17}{*}{ M2 } & H042001 & W. cibaria & & I041713 & L. plantarum & & I042505 & W. cibaria \\
\hline & H042002 & W. cibaria & & I041714 & L. plantarum & & I042506 & L. pseudomesenteroides \\
\hline & H042003 & W. cibaria & & I041715 & L. plantarum & & I042507 & L. pseudomesenteroides \\
\hline & H042004 & L. pseudomesenteroides & & I041716 & L. plantarum & & I042508 & W. cibaria \\
\hline & H042005 & L. pseudomesenteroides & & I041717 & L. plantarum & & I042509 & W. cibaria \\
\hline & H042006 & W. cibaria & & I041718 & L. plantarum & & I042510 & W. cibaria \\
\hline & H042007 & L. pseudomesenteroides & & I041719 & L. plantarum & & I042511 & L. lactis subsp. lactis \\
\hline & H042008 & W. cibaria & & I041720 & L. plantarum & & I042512 & L. pseudomesenteroides \\
\hline & H042009 & W. cibaria & M4 & I042201 & W. cibaria & & I042513 & L. lactis subsp. lactis \\
\hline & H042010 & W. cibaria & & I042202 & L. pseudomesenteroides & & I042514 & W. cibaria \\
\hline & H042011 & L. pseudomesenteroides & & I042203 & W. cibaria & & I042516 & W. cibaria \\
\hline & H042014 & L. pseudomesenteroides & & I042204 & W. cibaria & & I042517 & W. cibaria \\
\hline & H042015 & W. cibaria & & I042205 & W. cibaria & & I042518 & W. cibaria \\
\hline & H042016 & W. cibaria & & I042206 & W. cibaria & & I042519 & W. cibaria \\
\hline & H042017 & L. pseudomesenteroides & & I042207 & W. cibaria & & I042520 & W. cibaria \\
\hline & H042018 & W. cibaria & & I042208 & L. pseudomesenteroides & & & \\
\hline & H042021 & L. pseudomesenteroides & & I042209 & W. cibaria & & & \\
\hline
\end{tabular}




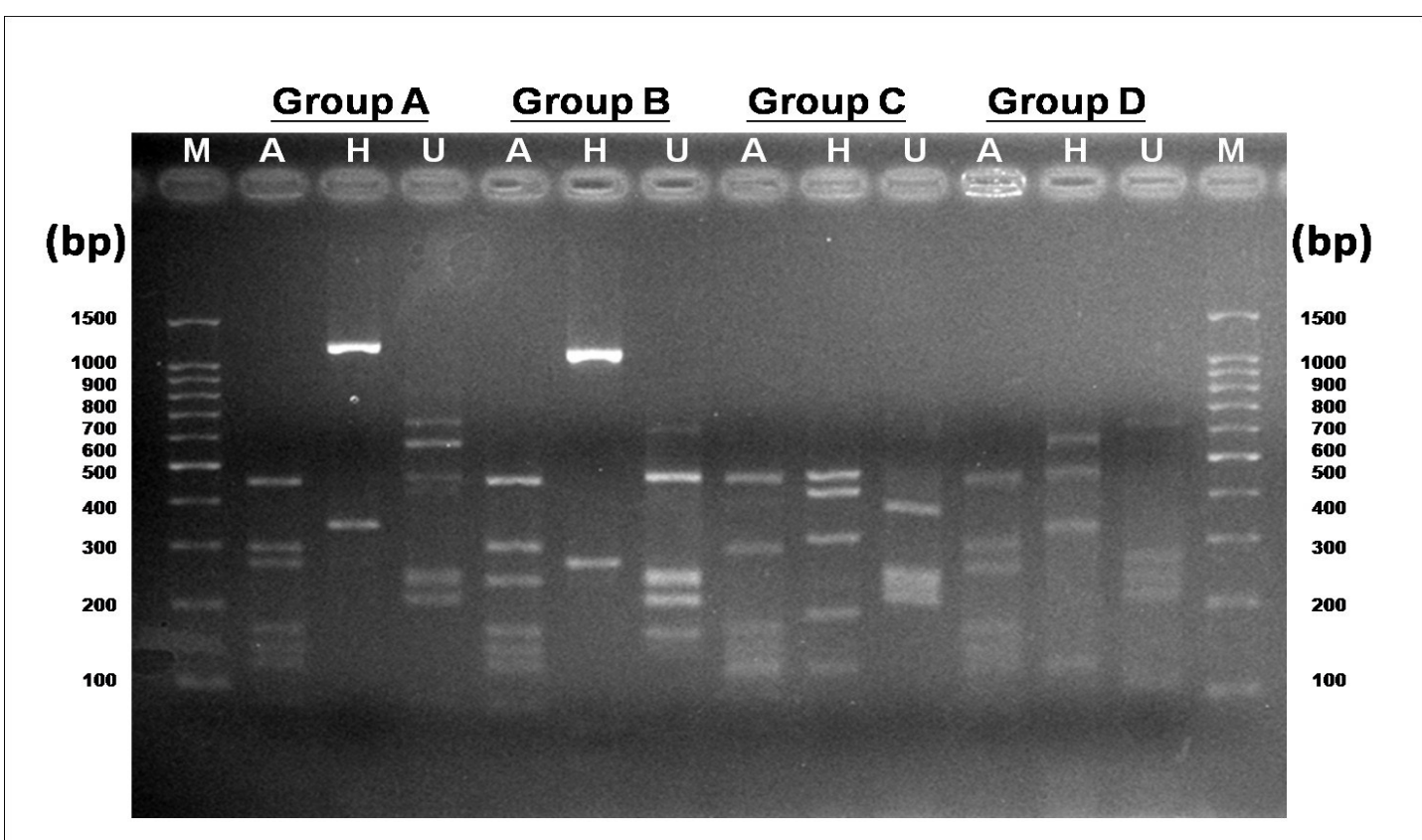

Figure 1. 16S rDNA RFLP patterns of AccII, HaeIII, and AluI digests from groups A to D. Lane M, size marker; A, AccII digestion patterns; H, HaeIII digestion patterns; U, AluI digestion patterns.

When assessing inhibitory activity against the indicator strain L. sakei $\mathrm{JCM} 1157^{\mathrm{T}}$, clear inhibition zones were observed for 10 W. cibaria and 1 L. lactis subsp. lactis isolates. However, only the same L. lactis subsp. lactis strain, I042513, showed inhibitory activity against L. monocytogenes ATCC 19111 and none of the isolates showed inhibitory activity against $H$. pylori ATCC $43504^{\mathrm{T}}$ (Table 2).

The effects of enzymes on the antimicrobial activity of the isolated substance from $10 \mathrm{~W}$. cibaria and one L. lactis subsp. lactis strains are shown in Table 2. All the antimicrobial substances were inactivated by proteinase $\mathrm{K}$ but not affected by treatment with catalase. However, trypsin inactivated the antimicrobial substance from $10 \mathrm{~W}$. cibaria but showed no effect on the antimicrobial substance from L. lactis subsp. lactis strain. Protease sensitivity assays demonstrated that the antimicrobial substance produced by the strain listed in Table 2 can be described as bacteriocin since its inhibitory activity was completely eliminated by treatment with enzyme proteinase $\mathrm{K}$ (13).

Table 2. Inhibition spectra and effect of enzymes on the bacteriocin produced by lactic acid bacteria from ripe mulberries.

\begin{tabular}{|c|c|c|c|c|c|c|c|}
\hline \multirow{3}{*}{ Isolated strain } & \multicolumn{3}{|c|}{ Indicator microorganisms } & \multicolumn{4}{|c|}{$\begin{array}{c}\text { Enzyme treatments } \\
\end{array}$} \\
\hline & \multirow{2}{*}{$\begin{array}{c}\text { L. sakei } \\
{\text { JCM } 1157^{\mathrm{T}}}\end{array}$} & \multirow{2}{*}{$\begin{array}{c}\text { L. monocytogenes } \\
\text { ATCC } 19111\end{array}$} & \multirow{2}{*}{$\begin{array}{c}\text { H. pylori } \\
\text { ATCC 43504 }^{\mathrm{T}}\end{array}$} & \multicolumn{4}{|c|}{ Diameter of the zone of inhibition $(\mathrm{mm})^{\alpha \beta}$} \\
\hline & & & & Control & Proteinase $\mathbf{K}$ & Trypsin & Catalase \\
\hline \multicolumn{8}{|l|}{ W. cibaria } \\
\hline H041703 & + & - & - & 11 & $\mathrm{~N}$ & $\mathrm{~N}$ & 11 \\
\hline H041706 & + & - & - & 11 & $\mathrm{~N}$ & $\mathrm{~N}$ & 11 \\
\hline H041710 & + & - & - & 11 & $\mathrm{~N}$ & $\mathrm{~N}$ & 11 \\
\hline H041713 & + & - & - & 11 & $\mathrm{~N}$ & $\mathrm{~N}$ & 11 \\
\hline H041715 & + & - & - & 10 & $\mathrm{~N}$ & $\mathrm{~N}$ & 10 \\
\hline H041718 & + & - & - & 11 & $\mathrm{~N}$ & $\mathrm{~N}$ & 11 \\
\hline H041719 & + & - & - & 11 & $\mathrm{~N}$ & $\mathrm{~N}$ & 11 \\
\hline H041720 & + & - & - & 11 & $\mathrm{~N}$ & $\mathrm{~N}$ & 11 \\
\hline H041721 & + & - & - & 11 & $\mathrm{~N}$ & $\mathrm{~N}$ & 11 \\
\hline H041722 & + & - & - & 11 & $\mathrm{~N}$ & $\mathrm{~N}$ & 11 \\
\hline \multicolumn{8}{|l|}{ L. lactis subsp. lactis } \\
\hline I042513 & + & + & - & 17 & $\mathrm{~N}$ & 17 & 17 \\
\hline
\end{tabular}

${ }^{\alpha}$ Wells ( $8 \mathrm{~mm}$ diameter) were filled with $100 \mu \mathrm{L}$ of culture supernatant.

${ }^{\beta}$ L. sakei JCM $1157^{\mathrm{T}}$ was used as the indicator strain.

Abbreviations: +, positive; -, negative; N, no inhibitory zone observed. 


\section{DISCUSSION}

$\mathrm{LAB}$ cultures were isolated from ripe fruits of all five mulberry farm samples, with differences in abundance and diversity evident among the farms (Table 1). Although the mulberry farms are 40 to $70 \mathrm{~km}$ apart from each other, the same dominant species, W. cibaria, was found in all five farms.

In addition, $W$. cibaria was also the most abundant species of $\mathrm{LAB}$ found in the mulberry farms, except for farm M3. Instead of $W$. cibaria, L. plantarum was the most abundant species of LAB found in farm M3. L. pseudomesenteroides was found only at farms M2, M4 and M5, while L. lactis subsp. lactis was only found at farm M5.

Species such as W. cibaria, L. plantarum and L. lactis subsp. lactis have been frequently found in environments associated with plants $(8,9,11,18)$. In a previous study, LAB associated with wine grapes was studied by Bae et al. (2). Differently from ripe mulberries, L. lindneri was the most abundant species of LAB found from wine grapes. In the case of tomato fruits, L. plantarum was the most abundant species of LAB found (8). Differences in LAB distribution, including not only species but also number, were observed among these fruits.

In this study, we focused not only on the distribution of LAB in mulberry farms, but also on the bacteriocin-producing ability of the isolates. A total of 11 strains, including $10 \mathrm{~W}$. cibaria and 1 L. lactis subsp. lactis, showed inhibitory activities against the indicator strain L. sakei JCM $1157^{\mathrm{T}}$ (Table 2). However, only the same strain of L. lactis subsp. lactis showed inhibitory activity against L. monocytogenes ATCC 19111. Bacteriocins from L. lactis subsp. lactis $(1,5,10,15)$ have been frequently studied. However, studies on bacteriocins from $W$. cibaria remain scarce (17).

The sensitivity of the substances to proteinase $\mathrm{K}$ or trypsin revealed their proteinaceous nature. In addition, no effect was observed with the catalase treatment, suggesting that the active agent is not involved in the $\mathrm{H}_{2} \mathrm{O}_{2}$ antimicrobial mechanism. The results obtained in this study were similar to the previous studies $(13,17)$.
Furthermore, it is interesting that 10 bacteriocin-producing W. cibaria strains were all distributed in farm M1. It is difficult to interpret why $W$. cibaria strains found in other mulberry farms did not produce bacteriocin, and why some $W$. cibaria produced bacteriocin but some did not. In the previous study of Trias et al. (18), W. cibaria strain TM128 effectively decreased the infection level of fungi. A similar result was also reported by Valerio et al. (19). It is therefore suspected that these bacteriocin-producing W. cibaria may protect mulberries from other microorganisms. However, more studies are necessary to test this hypothesis.

Besides W. cibaria strains, L. lactis subsp. lactis I042513 was the other bacteriocin-producing LAB strain found in this study. An additional experiment was performed to find more information about this bacteriocin. Nisin-specific PCR primers, NISL: 5'-CGAGCATAATAAACGGC-3' and NISR: 5'GGATAGTATCCATGTCTGAAC-3', were used for PCR amplification following the methods and conditions described by Villani et al. (20). The expected amplified band, located at $320 \mathrm{bp}$, was obtained. The PCR product was sequenced, and the DNA sequence was analyzed and found to encode a peptide containing an amino acid sequence with $100 \%$ coincidence to nisin Z (data not shown). However, more detailed protein analyses are necessary to support this result.

In conclusion, the results of this study suggest that various $\mathrm{LAB}$ are distributed in ripe mulberries. W. cibaria was the most abundant $\mathrm{LAB}$ in four mulberry farms, while $L$. plantarum was the most abundant $\mathrm{LAB}$ in a fifth mulberry farm. Many LAB isolated from ripe mulberries were found to produce bacteriocins. Future studies in our laboratory will characterize and identify the bacteriocins, and we anticipate that the bacteriocins from these LAB may be useful as biopreservatives. The authors hope that the results of this study will offer useful information for the improvement of mulberry cultivation.

\section{ACKNOWLEDGMENTS}

The authors would like to thank the National Science 
Council Taiwan for financially supporting this study, under Contract No. NSC 97-2313-B-130-001-MY2 grant to Y.S. Chen. The authors also would like to thank Dr. Ji-yuan Liang, Ms. Miao-ying Lin, Mr. Tzu-yu Liu and Ms. Yi-jen Wang for their kind cooperation in sampling and for technical assistance.

\section{REFERENCES}

1. Akcelik, O.; Tükel, C.; Özcengiz, G.; Akcelik, M. (2006). Characterization of bacteriocins from two Lactococcus lactis subsp. lactis isolates. Mol. Nutr. Food Res., 50: 306-313.

2. Bae, S.; Fleet, G.H.; Heard, G.M. (2006). Lactic acid bacteria associated with wine grapes from several Australian vineyards. J. Appl. Microbiol., 100: 712-727.

3. Chambel, L.; Chelo, I.M.; Zé-Zé, L.; Pedro, L.G.; Santos, M.A.; Tenreiro, R. (2006). Leuconostoc pseudoficulneum sp. nov., isolated from a ripe fig. Int. J. Syst. Evol. Microbiol., 56: 1375-1381.

4. Chen, Y.S.; Yanagida, F.; Shinohara, T. (2005). Isolation and identification of lactic acid bacteria from soil using an enrichment procedure. Lett. Appl. Microbiol., 40: 195-200.

5. Choi, H.J.; Cheigh, C.I.; Kim, S.B.; Pyun, Y.R. (2000). Production of a nisin-like bacteriocin by Lactococcus lactis subsp. lactis A164 isolated from kimchi. J. Appl. Microbiol., 88: 563-571.

6. Daeschel, M.A. (1989). Antimicrobial substances from lactic acid bacteria for use as food preservatives. Food Technol., 43: 164-167.

7. Duangjitcharoen, Y.; Kantachote, D.; Ongsakul, M.; Poosaran, N.; Chaiyasut, C. (2008). Selection of probiotic lactic acid bacteria isolated from fermented plant beverages. Pak. J. Biol. Sci., 11: 652-655.

8. Di Cagno, R.; Surico, R.F.; Paradiso, A.; De Angelis, M.; Salmon, J.C.; Buchin, S.; De Gara, L.; Gobbetti, M. (2009). Effect of autochthonous lactic acid bacteria starters on health-promoting and sensory properties of tomato juices. Int. J. Food Microbiol., 128: 473-483.

9. Escalante-Minakata, P.; Blaschek, H.P.; Barba de la Rosa, A.P.; Santos, L.; De León-Rodríguez, A. (2008). Identification of yeast and bacteria involved in the mezcal fermentation of Agave salmiana. Lett. Appl. Microbiol., 46: 626-630.

10. Kojic, M.; Strahinic, I.; Fira, D.; Jovcic, B.; Topisirovic, L. (2006). Plasmid content and bacteriocin production by five strains of Lactococcus lactis isolated from semi-hard homemade cheese. Can. J. Microbiol., 52: 1110-1120.

11. Kostinek, M.; Specht, I.; Edward, V.A.; Pinto, C.; Egounlety, M.; Sossa, C.; Mbugua, S.; Dortu, C.; Thonart, P.; Taljaard, L.; Mengu, M.; Franz, C.M.; Holzapfel, W.H. (2007). Characterisation and biochemical properties of predominant lactic acid bacteria from fermenting cassava for selection as starter cultures. Int. J. Food Microbiol., 114: 342-351.

12. Kozaki, M.; Uchimura, T.; Okada, S. (1992). Experimental Manual of Lactic Acid Bacteria. Tokyo, Asakurashoten, pp 29-72.

13. Noonpakdee, W.; Santivarangkna, C.; Jumriangrit, P.; Sonomoto, K.; Panyim, S. (2003) Isolation of nisin-producing Lactococcus lactis WNC 20 strain from nham, a traditional Thai fermented sausage. Int. J. Food Microbiol., 81:137-145.

14. Nyanga, L.K.; Nout, M.J.; Gadaga, T.H.; Theelen, B.; Boekhout, T.; Zwietering, M.H. (2007). Yeasts and lactic acid bacteria microbiota from masau (Ziziphus mauritiana) fruits and their fermented fruit pulp in Zimbabwe. Int. J. Food Microbiol., 120: 159-166.

15. Onda, T.; Yanagida, F.; Tsuji, M.; Ogino, S.; Shinohara, T. (1999). Isolation and characterization of the lactic acid bacterial strain GM005 producing an antibacterial substance from miso-paste product. Food Sci. Technol. Res., 5: 247-250.

16. Sato, H.; Yanagida, F.; Shinohara, T.; Yokotsuka, K. (2000). Restriction fragment length polymorphism analysis of $16 \mathrm{~S}$ rRNA genes in lactic acid bacteria isolated from red wine. J. Biosci. Bioeng., 90: 335-337.

17. Srionnual, S.; Yanagida, F.; Lin, L.H.; Hsiao, K.N.; Chen, Y.S. (2007). Weissellicin 110, a newly discovered bacteriocin from Weissella cibaria 110, isolated from plaa-som, a fermented fish product from Thailand. Appl. Environ. Microbiol., 73: 2247-2250.

18. Trias, R.; Bañeras, L.; Montesinos, E.; Badosa, E. (2008). Lactic acid bacteria from fresh fruit and vegetables as biocontrol agents of phytopathogenic bacteria and fungi. Int. Microbiol., 11: 231-236.

19. Valerio, F.; Favilla, M.; De Bellis, P.; Sisto, A.; de Candia, S.; Lavermicocca, P. (2009). Antifungal activity of strains of lactic acid bacteria isolated from a semolina ecosystem against Penicillium roqueforti, Aspergillus niger and Endomyces fibuliger contaminating bakery products. Syst. Appl. Microbiol., 32: 438-448.

20. Villani, F.; Aponte, M.; Blaiotta, G.; Mauriello, G.; Pepe, O.; Moschetti, G. (2001). Detection and characterization of a bacteriocin, garviecin L15 , produced by Lactococcus garvieae isolated from raw cow's milk. $J$. Appl. Microbiol., 90: 430-439.

21. Yanagida, F.; Chen, Y.S.; Onda, T.; Shinohara, T. (2005). Durancin L281A, a new bacteriocin from Enterococcus durans L28-1, isolated from soil. Lett. Appl. Microbiol., 40: 430-435.

22. Yanagida, F.; Srionnual, S.; Chen, Y.S. (2008). Isolation and characteristics of lactic acid bacteria from koshu vineyards in Japan. Lett. Appl. Microbiol., 47: 134-139.

23. Zhang, Q.J.; Tang, Y.B.; Chen, R.Y.; Yu, D.Q. (2007). Three new cytotoxic Diels-Alder-type adducts from Morus australis. Chem. Biodivers., 4: 1533-1540. 